\title{
Correlation between RAGE gene promoter methylation and diabetic retinal inflammation
}

\author{
SHIFENG KAN $^{1}$, JING WU ${ }^{2}$, CHENGXI SUN ${ }^{1}$, JING HAO $^{1}$ and ZHEN WU ${ }^{3}$ \\ ${ }^{1}$ Department of Clinical Laboratory, Qilu Hospital, Shandong University, Jinan, Shangdong 250012; \\ Departments of ${ }^{2}$ Pharmacy and ${ }^{3}$ Clinical Laboratory, The Second Hospital of Shandong University, \\ Jinan, Shangdong 250033, P.R. China
}

Received May 25, 2017; Accepted September 5, 2017

DOI: $10.3892 / \mathrm{etm} .2017 .5378$

\begin{abstract}
The methylation status of the receptor for advanced glycation end products (RAGE) gene promoter in peripheral blood mononuclear cells (PBMCs) of type 2 diabetic retinopathy (DR) patients was evaluated to investigate the correlation between RAGE gene promoter methylation and diabetic retinal inflammation. Eighty patients admitted and diagnosed as type 2 DR in Qilu Hospital, Shandong University during the period from October, 2013 to October, 2015 were enrolled in this study. They were the observation group and 40 healthy subjects were enrolled in the control group. PBMCs were collected from patients using density gradient centrifugation, and the methylation status of RAGE gene promoters was detected using methylation-specific PCP (MSP). Interleukin-1 $\beta$ (IL-1 $\beta$ ), IL-6 and tumor necrosis factor- $\alpha$ (TNF- $\alpha$ ) levels of in the serum were measured using enzyme-linked immunosorbent assay (ELISA). PBMCs in patients with positive RAGE gene promoter methylation were isolated and cultured and RAGE gene promoter methylation was inhibited using the demethylating agent, 5'-aza-2'-deoxycytidine (5-aza-dC). The methylation status of RAGE gene promoters in PBMCs was detected via MSP. IL-1 $\beta$, IL-6 and TNF- $\alpha$ levels in the supernatant of PBMC culture solution were evaluated using ELISA. MSP results showed that there were 26 cases $(32.50 \%)$ of RAGE gene promoter methylation in PBMCs in DR patients. RAGE gene promoters were methylated in all normal healthy subjects. IL- $1 \beta$, IL- 6 and TNF- $\alpha$ levels in serum for positive RAGE gene promoter methylation group were significantly lower than those in negative RAGE gene promoter methylation group $(\mathrm{p}<0.01)$. 5 -aza- $\mathrm{dC}$ inhibited the RAGE gene promoter methylation of PBMCs in patients with positive RAGE gene promoter methylation. The inhibition
\end{abstract}

Correspondence to: Dr Zhen Wu, Department of Clinical Laboratory, The Second Hospital of Shandong University, 247 Beiyuan Street, Jinan, Shandong 250033, P.R. China

E-mail: u778nh@163.com

Key words: receptor for advanced glycation end products, gene promoter methylation, diabetic retinopathy, inflammation of methylation in RAGE gene promoter increased the levels of IL- $1 \beta$, IL- 6 and TNF- $\alpha$ in supernatant of culture solution. In conclusion, RAGE gene promoter hypomethylation was detected in DR patients, indicating that RAGE gene promoter methylation could inhibit the diabetic retinal inflammation.

\section{Introduction}

With the improvement of living standards and the increase in the number of obese people, it is estimated that the number of diabetic patients in the world will reach 430 million by 2030 (1). Currently, China has the second largest population in the world, and the number of diabetic patients in China is expected to reach over 43.2 million by 2030 (2). Diabetic patients may suffer from various vascular complications due to metabolic and endocrine system disorders. This can eventually lead to diabetic retinopathy (DR) and loss of vision in diabetic patients. Recent studies have confirmed that inflammation plays a key role in the DR development and progression (3).

Results obtained from several previous studies have shown that long-term hyperglycemia can activate the advanced glycation end products (AGEs) and receptor for advanced glycation end products (RAGE) signal regulation pathway (4). AGEs are compounds formed by the long-term hyperglycemia and protein glycosylation, which play important roles in cell damage and chronic progression of diabetes (5). AGEs, combined with RAGE, can lead to intracellular oxidative stress, produce free radicals and activate nuclear factor NF- $\kappa$ B. In addition, AGEs can also promote the release of interleukin-1 $\beta$ (IL-1 $1 \beta$ ), IL-6 and tumor necrosis factor- $\alpha$ (TNF- $\alpha$ ), leading to the inflammatory response. RAGE is the key receptor protein of AGEs, and the abnormal expression of RAGE gene or a change in RAGE gene activity change may affect the development and progression of DR (6-8).

Studies have found that RAGE protein expression levels in DR patients is abnormally high (9). DNA methylation is a common type of epigenetic modification, and the gene expression can be lated when $\mathrm{CpG}$ islands are methylated in some gene promoter regions (10). To our knowledge, no conclusive research has been done on RAGE gene promoter methylation. In this study, the methylation status of RAGE gene promoters in peripheral blood mononuclear cells (PBMCs) was studied via methylation-specific PCR (MSP). IL-1 $\beta$, IL- 6 and TNF- $\alpha$ 
levels in serum were detected using enzyme-linked immunosorbent assay (ELISA). RAGE gene promoter methylation was inhibited via methylase inhibitor, 5'-aza-2'-deoxycytidine (5-aza-dC), and the effect of methylation on IL-1 $\beta$, IL-6 and TNF- $\alpha$ levels were studied. The correlation between RAGE gene promoter methylation and diabetic retinal inflammation was investigated.

\section{Materials and methods}

Materials and objects of study. 5-aza-dC (Sigma, St. Louis, MO, USA); RPMI-1640 medium, fetal bovine serum (FBS) (HyClone Laboratories, UT, USA); Ficoll Paque Plus (GE Healthcare, Bethesda, MD, USA); Epi-Tect Bisulfite kits (Qiagen, Nordrhein-Westfalen, Germany); IL-1 $\beta$, IL-6 and TNF- $\alpha$ ELISA kit (Beyotime Biotechnology Institute, Nantong, China); DNA extraction kit (Tiangen, Beijing, China); TaqDNA polymerase, dNTP mixture, DNA marker and primer synthesis (Takara, Dalian, China).

A total of 80 patients diagnosed with type 2 DR in Qilu Hospital, Shandong University from October, 2013 to October, 2015 were enrolled in this study. This included 44 males and 36 females aged $54.2 \pm 9.5$ years. Diabetic patients were diagnosed according to WHO standard in 1999 , and all patients were definitely diagnosed through the fundus fluorescein angiography and fundus examination. There were 40 healthy subjects without diabetes, heart disease, hypertension and other diseases in normal control group, including 23 males and 17 females aged 55.3 \pm 10.7 years. The participants had no specific heart, liver and lung diseases, and no acute and chronic infectious diseases and malignant tumors. The patients or their families signed the written informed consent, and this study was approved by the Ethics Committee of Qilu hospital.

Isolation and culture of PBMCs. Twenty microliters of venous blood was collected from each patient, and PBMCs were isolated using Ficoll-Paque Plus and cultured using the RPMI-1640 medium containing 10\% autologous serum under $5 \% \mathrm{CO}_{2}$ at $37^{\circ} \mathrm{C}$ for $2 \mathrm{~h}$. Suspended cells were washed and adherent cells were collected, and the media were replaced every $24 \mathrm{~h}$, followed by digestive passage when cell fusion was realized.

Detection of RAGE gene promoter methylation in PBMCs via MSP. Total DNA was extracted using DNA extraction kit, and the DNA content and purity (qualified if A260/A280>1.8) were detected using ultraviolet spectrophotometer (U-3010; Hitachi, Tokyo, Japan). Total DNA extracted received bisulfite modification according to instructions provided by EpiTect Bisulfite kits, and methylation-specific PCR and unmethylated-specific PCR were performed for modified DNA. PCR reaction was $2 \mu 1$ 10X PCR buffer ( $20 \mu 1$ in total), 20 pmol primers (Fig. 1, sequence), dNTP (final concentration of $0.2 \mathrm{mmol} / \mathrm{l}$ ), $\mathrm{MgCl}_{2}$ (final concentration of $1.0 \mathrm{mmol} / \mathrm{l}$ ), 1 unit Hot Start Taq enzyme and 100 ng modified DNA template. The specific conditions for PCR amplification were as follows: $95^{\circ} \mathrm{C}$ for $5 \mathrm{~min}$, degeneration at $95^{\circ} \mathrm{C}$ for $45 \mathrm{sec}$, annealing at $67^{\circ} \mathrm{C}$ for $45 \mathrm{sec}$, extension at $72^{\circ} \mathrm{C}$ for $60 \mathrm{sec}$, a total of 30 cycles, and reaction termination after extension at $72^{\circ} \mathrm{C}$
Table I. RAGE gene promoter methylated and unmethylated primer sequence.

\begin{tabular}{lcc}
\hline Primer & Primer sequences & $\begin{array}{c}\text { Product } \\
\text { size (bp) }\end{array}$ \\
\hline RAGE-MF & 5'-TTTTAGAATTTTTTTTAGAATTCGA-3' & 181 \\
RAGE-MR & 5 5'-CTTACACTTCAACACCAATAACTCG-3' & \\
RAGE-UF & 5'-TTTTAGAATTTTTTTTAGAATTTGA-3' & 186 \\
RAGE-UR & 5'-TACACTTCAACACCAATAACTCACC-3' & \\
\hline
\end{tabular}

RAGE, receptor for advanced glycation end products; F, forward; R, reverse.

for $10 \mathrm{~min}$. PCR product was transferred to $2 \%$ agarose gel electrophoresis, ethidium bromide staining, photography and result analysis using gel-imaging system (UVP, LLC, Upland, CA, USA) (Table I).

Detection of $I L-1 \beta$, IL- 6 and TNF- $\alpha$ contents in serum via ELISA. Three milliliters fasting venous blood was drawn from DR patients and those in normal control group in the early morning, and centrifuged after water bath at $37^{\circ} \mathrm{C}$ for $10 \mathrm{~min}$. The serum samples were collected and stored in the refrigerator at $-20^{\circ} \mathrm{C}$, and the IL- $1 \beta$, IL- 6 and TNF- $\alpha$ contents in serum were detected according to instructions of ELISA kit.

Detection of effect of 5-aza-dC on RAGE gene promoter methylation in PBMCs via MSP. PBMCs of DR patients with positive RAGE gene promoter methylation were cultured according to standard method, and cells were divided into non-treatment group (NT) and 5-aza-dC treatment group. Cells in NT group were cultured using the normal culture method, while cells in 5-aza-dC treatment group were treated with 5 -aza-dC with the final concentration of $5 \mu \mathrm{mol} / 1$. After $24 \mathrm{~h}$, cells were digested by trypsin and collected, and the total DNA was extracted using the DNA extraction kit. The RAGE gene promoter methylation in each group was then detected.

Detection of effect of 5-aza-dC on IL-1 $\beta, I L-6$ and TNF- $\alpha$ in culture supernatant of PBMCs via ELISA. PBMCs in logarithmic growth phase were collected and added into each well ( $2 \times 10^{5}$ cells $\left./ \mathrm{ml}\right)$. After the culture of PBMCs suspension in the 6-well plate for $24 \mathrm{~h}$, the cells were treated according to the method in 1.5. After $24 \mathrm{~h}, 50 \mu \mathrm{l}$ culture supernatant was drawn and the contents of IL- $1 \beta$, IL- 6 and TNF- $\alpha$ in culture supernatant were detected according to instructions of ELISA kit.

Statistical analysis. SPSS 17.0 (IBM Corp., Armonk, NY, USA) was used for data processing in this study. Measurement data were presented as mean \pm standard deviation. LSD test was performed for multiple comparisons test. $\mathrm{p}<0.05$ indicates a statistically significant difference.

\section{Results}

RAGE gene promoter methylation in PBMCs. All RAGE gene promoters in PBMCs of 40 healthy adults were methylated, and the detection rate of RAGE gene promoter methylation 


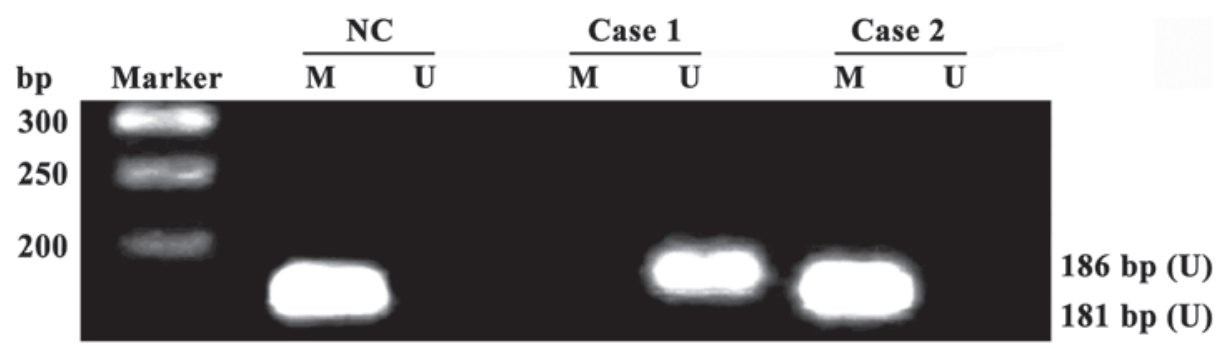

Figure 1. Detection of receptor for advanced glycation end products (RAGE) gene promoter methylation in peripheral blood mononuclear cells (PBMCs) of diabetic retinopathy (DR) patients and healthy adults via methylation-specific PCP (MSP); all RAGE promoters in healthy adults are methylated, and some promoters in DR patients are not methylated; Ma, Takara DL2000 DNA Marker; case1-case2, DR patients; NC, normal control group; U, unmethylated-specific PCR amplification results; M, methylation-specific PCR amplification results.

A

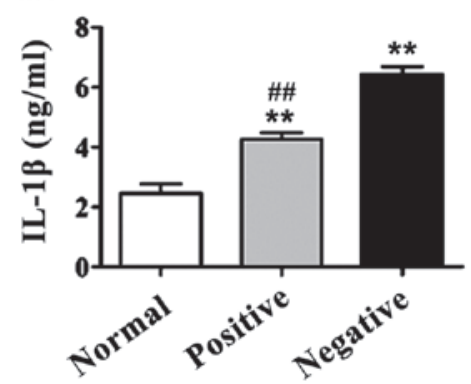

B

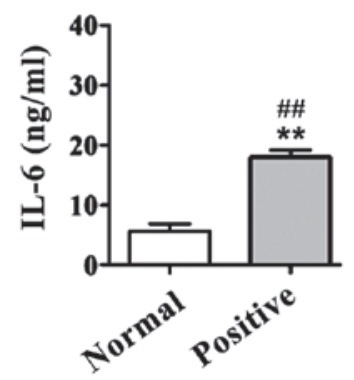

C

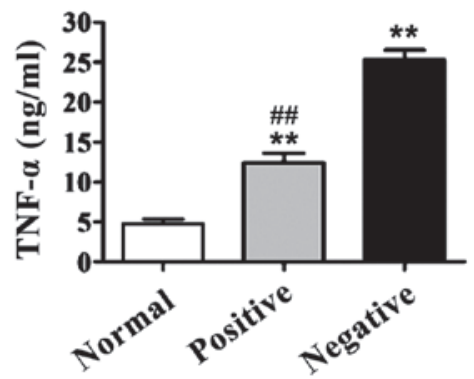

Figure 2. Detection of interleukin-1 $\beta$ (IL-1 $\beta$ ), IL-6 and tumor necrosis factor- $\alpha$ (TNF- $\alpha$ ) contents in serum via enzyme-linked immunosorbent assay (ELISA). Compared with those in normal control group, IL-1 $\beta$, IL- 6 and TNF- $\alpha$ contents in serum of diabetic retinopathy (DR) patients are significantly increased, ${ }^{* *} \mathrm{p}<0.01$. The contents of IL-1 $\beta$, IL- 6 and TNF- $\alpha$ in serum of patients with positive receptor for advanced glycation end products (RAGE) gene promoter methylation are significantly decreased compared with those of patients with negative RAGE gene promoter methylation, ${ }^{\# \#}$ p $<0.01$. (A) IL-1 $\beta$ content in serum of patients; (B) IL-6 content in serum of patients; (C) TNF- $\alpha$ content in serum of patients.

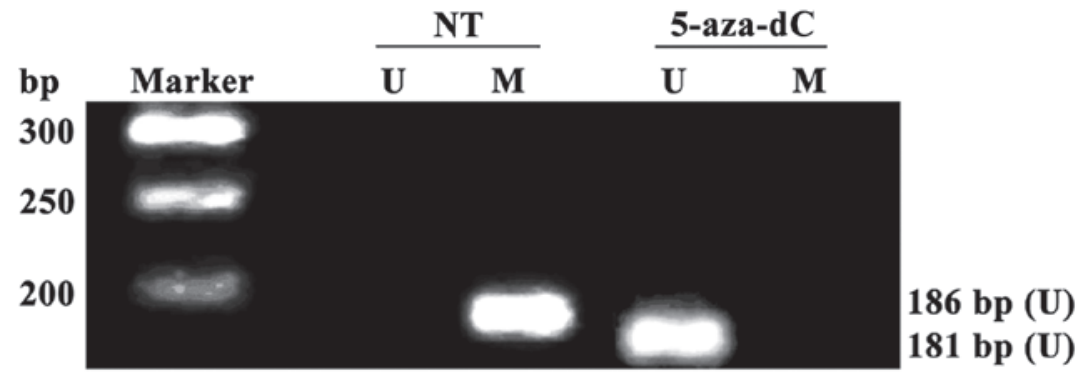

Figure 3. Detection of receptor for advanced glycation end products (RAGE) gene promoter methylation in peripheral blood mononuclear cells (PBMCs) via methylation-specific PCP (MSP). No methylation is detected in cells in 5'-aza-2'-deoxycytidine (5-aza-dC) treatment group. Ma, Takara DL2000 DNA Marker; $\mathrm{U}$, unmethylated-specific PCR amplification results; M, methylation-specific PCR amplification results.

A

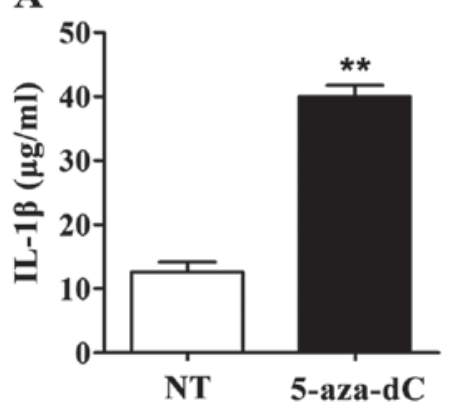

B

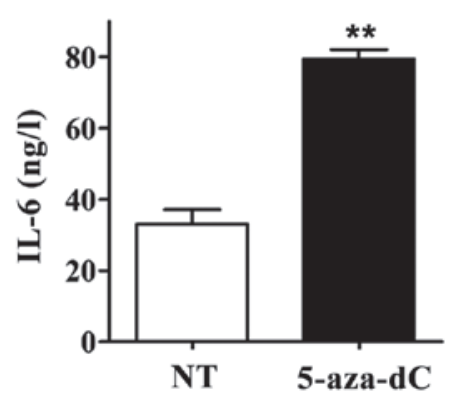

C

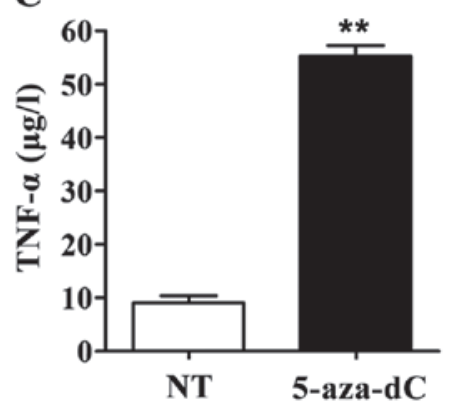

Figure 4. Effect of 5'-aza-2'-deoxycytidine (5-aza-dC) on the levels of interleukin-1 $\beta$ (IL-1 $\beta$ ), IL-6 and TNF- $\alpha$ in cell supernatants. Enzyme-linked immunosorbent assay (ELISA) showed that the levels of IL-1 $\beta$, IL-6 and TNF- $\alpha$ in cell supernatant in 5-aza-dC treatment group were significantly increased compared with those in NT group, ${ }^{* *}$ p $<0.01$. (A) IL-1 $\beta$ content in culture supernatant of peripheral blood mononuclear cells (PBMCs); (B) IL-6 content in culture supernatant of PBMCs; (C) TNF- $\alpha$ content in culture supernatant of PBMCs. 
in PBMCs of DR patients was $32.50 \%$ (26/80) (Fig. 1). The methylation rate of RAGE gene promoters had a significant difference in PBMCs between DR patients and healthy adults $(\mathrm{p}<0.01)$.

$I L-1 \beta, I L-6$ and TNF- $\alpha$ levels in serum. In DR group, the serum levels of IL-1 $\beta$, IL- 6 and TNF- $\alpha$ of patients with and without RAGE gene promoter methylation were higher than those in the normal control group $(\mathrm{p}<0.01)$. IL-1 $\beta$, IL-6 and TNF- $\alpha$ levels in patients with positive RAGE gene promoter were significantly lower than those of patients with negative RAGE gene promoter methylation, and there were significant differences $(\mathrm{p}<0.01)$ (Fig. 2).

Effect of 5-aza-dC on RAGE gene promoter methylation in PBMCs of patients. All RAGE gene promoters were methylated in non-treatment group (NT), and no RAGE gene promoter methylation was detected in 5-aza-dC treatment group, suggesting that the RAGE gene promoter methylation in PBMCs of DR patients with positive RAGE gene promoter methylation can be completely inhibited after intervention with 5-aza-dC for $24 \mathrm{~h}$ (Fig. 3A).

Effect of 5-aza-dC on IL-1 $\beta, I L-6$ and TNF- $\alpha$ levels in culture supernatant of PBMCs. When the RAGE gene promoter methylation in PBMCs was inhibited by 5 -aza-Dc, IL-1 $\beta$, IL-6 and TNF- $\alpha$ levels in culture supernatant in the 5-aza-dC group were significantly higher than those in the NT group. All differences were statistically significant $(\mathrm{p}<0.01)$ (Fig. 4), suggesting that inhibiting the RAGE gene promoter methylation in PBMCs can significantly increase the levels of IL-1 $\beta$, IL- 6 and TNF- $\alpha$ in culture supernatant of PBMCs.

\section{Discussion}

Diabetic retinopathy is a serious complication in patients suffering from diabetes, which can cause serious lesions in retinal capillaries, and eventually may lead to blindness (11). RAGE is a transmembrane receptor with multiple ligands (12). RAGE, combined with its ligand AGEs, can activate a series of signaling pathways, which may lead to synthesis and release of different cytokines and growth factors. It can cause vascular endothelial injury, abnormal cellular matrix proliferation and other pathological changes, ultimately participating in the occurrence and development of diabetic complications (13). Epidemiological studies have confirmed that the activation of RAGE signaling pathways plays an important role in the inflammatory response of human body and vascular disease in diabetic patients (14).

Prior studies showed that inflammatory symptoms can de seen in diabetic patients, and IL- $1 \beta$, IL- 6 , TNF- $\alpha$ expressions may abnormally increase in these patients (15). Results obtained from other studies revealed that hyperglycemia can promote the secretion of IL-1 $\beta$, IL- 6 and IL- 1 . It was also discovered that IL- 6 can promote the B lymphocyte differentiation, and the production of the antibody-activated T lymphocytes, it may also promote the death of pancreatic islet B cells (16). At the same time, IL-1 and IL-6 may promote the proliferation of smooth muscle cells and can increase the endothelial permeability, and cause vascular injury (17).
TNF- $\alpha$ mediates inflammatory responses, and is an important index of inflammation and tissue damage, which can damage the blood-retinal barrier and increase the permeability of retinal vessels (18). Studies have found that TNF- $\alpha$ increases the adhesion of neutrophils and retinal endothelial cells through increasing the activity of glycosylase (19).

In this study, MSP was used to detect the methylation status of RAGE gene promoters in PBMCs. The results showed that the methylation rate of RAGE gene promoters in PBMCs of DR patients was $32.50 \%$, and all RAGE gene promoters in PBMCs in healthy adults were methylated. The results of ELISA showed that IL-1 $\beta$, IL- 6 and TNF- $\alpha$ levels in serum of patients with positive RAGE gene promoter methylation were significantly lower than those of patients with negative RAGE gene promoter methylation. In order to confirm the effect of RAGE promoter methylation on diabetic retinal inflammation, 5-aza-dC was used to inhibit the RAGE gene promoter methylation in PBMCs. Consequently, the effect of inhibiting RAGE gene promoter methylation on IL- $1 \beta$, IL- 6 and TNF- $\alpha$ levels in PBMC was investigated. Results showed that inhibiting RAGE gene promoter methylation could significantly increase IL-1 $\beta$, IL- 6 and TNF- $\alpha$ levels in the supernatant, indicating that RAGE gene promoter methylation can inhibit diabetic retinal inflammation.

Yamamoto et al studied the role of RAGE in diabetic nephropathy using transgenic technology, and they discovered that the RAGE gene knockout can slow down the occurrence of diabetic nephropathy (20). In addition, in other studies it was revealed that lesions may occur in retinas when RAGE protein is overexpressed in mice with transgenic diabetes. Also, it was shown that the retinal inflammation symptoms were significantly improved when the RAGE overexpression in diabetic mice was inhibited $(21,22)$. In this study, it was demonstrated that RAGE gene promoter methylation could inhibit diabetic retinal inflammation.

We conclud that RAGE gene promoter methylation reduce diabetic retinal inflammation. Also, DNA methylation is a way to regulate gene expression, therefore inducing RAGE gene promoter methylation may become a new method for reducing the inflammation of DR patients.

\section{References}

1. Wild S, Roglic G, Green A, Sicree R and King H: Global prevalence of diabetes: Estimates for the year 2000 and projections for 2030. Diabetes Care 27: 1047-1053, 2004.

2. Mehuys E, De Bolle L, Van Bortel L, Annemans L, Van Tongelen I, Remon JP and Giri M: Medication use and disease management of type 2 diabetes in Belgium. Pharm World Sci 30: 51-56, 2008.

3. Studholme S: Diabetic retinopathy. J Perioper Pract 18: 205-210, 2008.

4. Lee K, Ahn JM, Kim EK and Kim TI: Comparison of optical quality parameters and ocular aberrations after wavefrontguided laser in-situ keratomileusis versus wavefront-guided laser epithelial keratomileusis for myopia. Graefes Arch Clin Exp Ophthalmol 251: 2163-2169, 2013.

5. Yan SF, D'Agati V, Schmidt AM and Ramasamy R: Receptor for advanced glycation endproducts (RAGE): A formidable force in the pathogenesis of the cardiovascular complications of diabetes and aging. Curr Mol Med 7: 699-710, 2007.

6. Bierhaus A, Hofmann MA, Ziegler R and Nawroth PP: AGEs and their interaction with AGE-receptors in vascular disease and diabetes mellitus. I. The AGE concept. Cardiovasc Res 37: 586-600, 1998.

7. Singh R, Barden A, Mori T and Beilin L: Advanced glycation end-products: A review. Diabetologia 44: 129-146, 2001. 
8. Adamis AP: Is diabetic retinopathy an inflammatory disease? $\mathrm{Br}$ J Ophthalmol 86: 363-365, 2002.

9. Seiler T, Kaemmerer M, Mierdel P and Krinke HE: Ocular optical aberrations after photorefractive keratectomy for myopia and myopic astigmatism. Arch Ophthalmol 118: 17-21, 2000.

10. Jubb AM, Bell SM and Quirke P: Methylation and colorectal cancer. J Pathol 195: 111-134, 2001.

11. Lam DW and LeRoith D: The worldwide diabetes epidemic. Curr Opin Endocrinol Diabetes Obes 19: 93-96, 2012.

12. Schmidt AM, Vianna M, Gerlach M, Brett J, Ryan J, Kao J, Esposito C, Hegarty H, Hurley W, Clauss M, et al: Isolation and characterization of two binding proteins for advanced glycosylation end products from bovine lung which are present on the endothelial cell surface. J Biol Chem 267: 14987-14997, 1992.

13. Logsdon CD, Fuentes MK, Huang EH and Arumugam T: RAGE and RAGE ligands in cancer. Curr Mol Med 7: 777-789, 2007.

14. Yan SF, Ramasamy R and Schmidt AM: Mechanisms of disease: Advanced glycation end-products and their receptor in inflammation and diabetes complications. Nat Clin Pract Endocrinol Metab 4: 285-293, 2008.

15. Carey AL, Lamont B, Andrikopoulos S, Koukoulas I, Proietto J and Febbraio MA: Interleukin-6 gene expression is increased in insulin-resistant rat skeletal muscle following insulin stimulation. Biochem Biophys Res Commun 302: 837-840, 2003.

16. Aljada A, Garg R, Ghanim H, Mohanty P, Hamouda W, Assian E and Dandona P: Nuclear factor-kappaB suppressive and inhibitorkappaB stimulatory effects of troglitazone in obese patients with type 2 diabetes: Evidence of an antiinflammatory action? J Clin Endocrinol Metab 86: 3250-3256, 2001.

17. André-Schmutz I, Hindelang C, Benoist C and Mathis D Cellular and molecular changes accompanying the progression from insulitis to diabetes. Eur J Immunol 29: 245-255, 1999.
18. Krylova IN, Sablin EP, Moore J, Xu RX, Waitt GM, MacKay JA, Juzumiene D, Bynum JM, Madauss K, Montana V, et al: Structural analyses reveal phosphatidyl inositols as ligands for the NR5 orphan receptors SF-1 and LRH-1. Cell 120: 343-355, 2005.

19. Ben-Mahmud BM, Chan WH, Abdulahad RM, Datti A, Orlacchio A, Kohner EM and Chibber R: Clinical validation of a link between TNF- $\alpha$ and the glycosylation enzyme core 2 GlcNAc-T and the relationship of this link to diabetic retinopathy. Diabetologia 49: 2185-2191, 2006.

20. Yamamoto Y, Kato I, Doi T, Yonekura H, Ohashi S, Takeuchi M, Watanabe T, Yamagishi S, Sakurai S, Takasawa S, et al: Development and prevention of advanced diabetic nephropathy in RAGE-overexpressing mice. J Clin Invest 108: 261-268, 2001.

21. Yamagishi S, Nakamura K, Matsui T, Noda Y and Imaizumi T: Receptor for advanced glycation end products (RAGE): A novel therapeutic target for diabetic vascular complication. Curr Pharm Des 14: 487-495, 2008.

22. Reiniger N, Lau K, McCalla D, Eby B, Cheng B, Lu Y, Qu W, Quadri N, Ananthakrishnan R, Furmansky M, et al: Deletion of the receptor for advanced glycation end products reduces glomerulosclerosis and preserves renal function in the diabetic OVE26 mouse. Diabetes 59: 2043-2054, 2010.

This work is licensed under a Creative Commons Attribution-NonCommercial-NoDerivatives 4.0 International (CC BY-NC-ND 4.0) License. 